Turró-Garriga O, Garre-Olmo J, Vilalta-Franch J, Conde-Sala J, de Gracia-Blanco M, López-Pousa S. Burden associated with the presence of anosognosia in Alzheimer's disease. International Journal of Geriatric Psychiatry 2013; 28: 291-297.

\title{
Burden associated with the presence of anosognosia in Alzheimer's disease
}

Oriol Turró-Garriga ${ }^{1}$, Josep Garre-Olmo ${ }^{1-2}$, Joan Vilalta-Franch ${ }^{1-3}$, Josep Lluís Conde-Sala ${ }^{4}$, Manuel de Gracia Blanco ${ }^{2}$ Secundino López-Pousa ${ }^{1-3}$.

${ }^{1}$ Research unit, Institut d'Assistència Sanitària. Girona

${ }^{2}$ Department of Psychology, University of Girona.

${ }^{3}$ Dementia Unit; Hospital Santa Caterina, Salt

${ }^{4}$ Department of Developmental Psychology, University of Barcelona.

Address for correspondence: Josep Garre Olmo; C/ Dr. Castany s/n, 17190 Salt (Girona), tel.: +34 972 182600- ext. 1831, fax: +34 972 189017, e-mail: josep.garre@ias.scs.es

Running head: Anosognosia \& Caregiver's burden in AD

Key words: Alzheimer disease $[\mathrm{MeSH}]$, caregivers [MeSH], awareness [MeSH], Agnosia [MeSH], Denial (Psychology), ADL [MeSH].

Key points: The presence of anosognosia in Alzheimer's disease patients is an independent factor for increases the burden of their caregivers. The presence of anosognosia increasing physical wear, social isolation, dependence and tension related to patient care.

Word count of body text: 2,927

Number of tables: 2 


\section{SUMMARY}

Objectives Anosognosia is the lack of deficit awareness, and it is a common symptom in patients with Alzheimer's disease (AD). The objective of this study was to assess the relationship between anosognosia and caregiver burden. Methods This was a cross-sectional, analytical study of patients who were diagnosed with AD and their caregivers. Anosognosia was evaluated using the Experimenter Rating Scale (ERS), and caregiver burden was evaluated using the Burden Interview (BI). Using the BI's comprehensive scoring and each of its five factors as dependent variables, six linear regression models were adjusted to determine the effect of anosognosia on caregiver burden. Results The sample consisted of 124 patients and 124 caregivers. The mean patient age was 78.9 years $(\mathrm{SD}=6.9)$; the mean caregiver age was 59.7 years $(\mathrm{SD}=13.6)$, and $66.6 \%$ of the caregivers were women. The prevalence of anosognosia was $24.2 \%$ (95\% confidence interval=16.7-33.3). The degree of caregiver burden was associated with the degree of anosognosia $\left(\mathrm{r}^{2}=.426\right.$; standardised beta $\left.[\beta \mathrm{s}]=.346 ; \mathrm{p}<.001\right)$, which explained $14.7 \%$ of the variance. For the BI factors, the ERS was associated with physical and social burden $\left(\mathrm{r}^{2}=.452 ; \beta \mathrm{s}=.378 ; \mathrm{p}<.001\right)$, relationship of dependence $\left(\mathrm{r}^{2}=.301\right.$; $\beta \mathrm{s}=.203 ; \mathrm{p}=.010)$ and emotional stress $\left(\mathrm{r}^{2}=.212 ; \beta \mathrm{s}=.227 ; \mathrm{p}=.014\right)$. Conclusions The presence of anosognosia in patients with $\mathrm{AD}$ is an independent factor that increases caregiver burden by increasing physical wear, social isolation, dependence and tension related to patient care.

\section{KEY WORDS}

Alzheimer disease [MeSH], caregivers [MeSH], awareness [MeSH], Agnosia [MeSH], Denial (Psychology), ADL [MeSH]. 


\section{INTRODUCTION}

The caregiver burden that is associated with the informal care of patients with a dementia is defined as the caregiver's perception of the physical, emotional, economic and social costs of the caregiving relationship (Burns \& Rabins, 2000).

For the caregivers of patients with Alzheimer's disease (AD), the perception of burden is determined by distinct factors as follows: first, by aspects that are related to the patient's course of illness, disability level, psychological and behavioural disorders and/or comorbidities (Clyburn, 2000; Gaugler, 2000; Yueh-Feng \& Guerriero-Austrom, 2005); second, by the caregiver's physical, emotional, economic and social characteristics (BadiaLlach, 2004; Burns \& Rubins, 2000); and third, by the caregiver's coping capacity, mental flexibility, ability to manage the patient and/or social and health resources (Mahoney, 2005; Martín-Carrasco, 2009; Sörensen, 2002).

Progressive cognitive impairment and invalidating functional disability are the principal characteristics of $\mathrm{AD}$, and they are the main causes of caregiver burden (TurróGarriga, 2008; Zarit, 1980). The perception of burden is complicated by the psychological and behavioural symptoms of dementia (PBSD) (Finkel \& Burns, 2000), which especially include psychotic disorders, aggression, depression and sleep disorders (Sörensen 2002; TurróGarriga, 2008; Yueh-Feng, 2005). Nevertheless, certain patient and caregiver characteristics (such as their previous relationship), contextual aspects (such as the caregiver's work situation), patient comorbidities or harmful behaviors (like active alcohol abuse) and cohabitation with the patient can contribute significantly to the caregiver's perception of burden (Conde-Sala, 2010; Garre-Olmo, 2000; Turró-Garriga, 2008).

Anosognosia is the lack of awareness of deficits; it can appear in patients who are in the initial stages of AD and significantly disrupt the patient's environment (Aalsten, 2005; Awad \& Voruganti, 2008; Clare 2003; Kashiwa, 2005; Starkstein 2006). The prevalence of 
anosognosia is between $20 \%$ and $43 \%$ of patients with mild or moderate AD (Aalsten, 2006; Migliorelli, 1995). Because anosognosia is associated with an increased caregiver burden (Seltzer, 1997; DeBettignies, 1990), the high prevalence of anosognosia suggests that a large number of caregivers have added difficulties in their caregiving activities. Studies of patients with anosognosia in the context of pathologies other than AD have shown that the presence of anosognosia was related to increased difficulty in patient management, less adherence to pharmacological and non-pharmacological treatments and early institutionalisation (Madalia \& Thysen, 2008; Koltai, 2001; Clare, 2003). The objective of this study was to determine the relationship between the presence of anosognosia in patients with mild and moderate AD and caregiver burden, both overall and within various dimensions of caregiver burden.

\section{METHODS}

Design

This study was cross-sectional and analytical.

\section{Patients}

The sample consisted of ambulatory patients with $\mathrm{AD}$ who were diagnosed at the Dementia Unit of the Santa Caterina's Hospital (Girona). The inclusion criteria were as follows: a) probable $\mathrm{AD}$ diagnosis according to the criteria of the National Institute of Neurological and Communicative Disorders and Stroke - Alzheimer's Disease and Related Disorders Association (NINCDS-ADRDA; McKhann et al, 1984); b) mild or moderate severity according to the criteria of the Cambridge Examination for Mental Disorders of the Elderly - Revised (CAMDEX-R; Roth et al, 1986); and c) the presence of a close and reliable caregiver. Institutionalisation was an exclusion criterion. No other information about the medical history or psychosocial antecedents was used as participation criteria. The study protocol was evaluated and approved by the Institutional Review Board of the Institut 
d'Assistència Sanitària. The sample size was calculated to achieve a power of $80 \%$ to detect at least $5 \%$ of the variance that was explained by the introduction of a new variable to a multiple linear regression model and assuming that the six clinical variables initially provided a determination coefficient of $45 \%$. For a significance level of $5 \%$, it was necessary to include a minimum of 100 participants.

\section{Variables and instruments}

The data regarding the patients' and caregivers' sociodemographics (age, sex, education, marital status, relationship with the patient and cohabitation) were recorded in a standardised format.

Anosognosia was assessed using the Experimenter Rating Scale (ERS), which is a clinical judgment scale with four categories that evaluate the patient's awareness of deficits (from major to minor) using examination and direct questions (Bisiach, Vallar, Perani, Papagno \& Berti, 1986). The four categories are as follows: 1) spontaneous expression of deficits and concern about them, 2) mentioning difficulty completing specific tests, 3) referring to deficits after direct questions while minimising their frequency and consequences and 4) denial of deficits. The patients included in the last category were determined to have anosognosia.

The perception of caregiver burden was evaluated using the Burden Interview (BI; Martín, 1996; Zarit, 1980). This is a self-administered test that consists of 22 Likert-type response items. The responses reflect the caregivers' common perceptions and feelings. The score ranges from 22 to 110 points, and higher scores indicate higher perceived burden. Its intra-class correlation coefficient is .71, the Cronbach's alpha internal consistency is $\alpha=.91$ and the reliability test-retest is $\alpha=.86$. An earlier study of the BI's factorial distribution identified a five-dimensional structure as follows: physical and social burden $(\alpha=.90)$, stress 
( $\alpha=.73$ ), feelings of guilt $(\alpha=.90)$, emotional stress $(\alpha=.68)$ and relationship of dependence $(\alpha=.59$; Turró-Garriga et al, 2008).

Cognitive function was evaluated with the Cambridge Cognitive Examination Revised (CAMCOG-R), which objectively assesses multiple superior mental functions. The scores range from 0 to 105 points and the lower scores indicate greater degrees of cognitive deterioration (Roth, 1986; Vilalta-Franch, 1990).

Functional capacity and autonomy were analysed using the Disability Assessment in Dementia (DAD), which is a functional assessment scale for patients with dementia that is administered via an interview with the caregiver. It is composed of 40 dichotomous response (yes/no) items (17 items correspond to basic activities of daily living and 23 correspond to instrumental activities of daily living). This scale presents an intra-class correlation coefficient of $r=.96$, and Cronbach's $\alpha=.59$ (Gelinas, Gauthier, McIntyre \& Gauthier, 1999).

The presence of neuropsychiatric symptomology was evaluated with the Neuropsychiatric Inventory (NPI), which was administered to the caregiver. The 12 subscales briefly evaluate the patient's frequency and severity of delirium, hallucinations, agitation/ aggression, depression, anxiety, euphoria, apathy, disinhibition, irritability/ susceptibility, deambulation, sleep alterations and eating disorders. The scores range from 0 to 144 points and the tool has an overall internal consistency of .88 (Cummings, 1994; Vilalta-Franch, 1999).

\section{Statistical analysis}

A descriptive analysis was implemented for the clinical and sociodemographic characteristics; absolute and relative frequencies were used for the qualitative variables, and central tendency and dispersion measures were used for the quantitative variables.

The differences in the participants' clinical and sociodemographic characteristics were analysed according to presence or absence of anosognosia. Parametric and non-parametric 
techniques were used for the quantitative variables, and the chi-squared test was used for the qualitative variables. The effect size was calculated for the differences in the characteristics (differences between the patients with and without anosognosia) using Cohen's statistical d (Cohen, 1992).

With the objective of determining the effect of anosognosia on caregiver burden, six linear regression models with successive steps were adjusted. The first model was adjusted with the overall BI score as a dependent variable, and the other five models were adjusted with the scores of each of the latent factors of the BI. For all of the models, the patient and caregiver clinical characteristics and sociodemographics were introduced as independent variables. The explained variance of the independent variables on the caregiver burden was determined using the contribution index $\left[\left(\mathrm{r}^{2} * \beta \mathrm{s}\right) / 100\right]$.

The statistical analysis was performed with the Statistical Package for Social Sciences (SPSS) for Windows v. 15.0, with a significance level that was equal to or less than .05 and confidence intervals (CI) at $95 \%$.

\section{RESULTS}

The sample included 124 patients with an average age of 78.9 years $(\mathrm{SD}=6.9$; range $=59$ to 92 years), $68.7 \%$ of whom were women. Married patients accounted for $60.5 \%$ of the sample, whereas $39.5 \%$ of the patients were widowed or separated. Regarding education levels, $49.2 \%$ of the patients had completed primary school (six to eight years of schooling), $38.2 \%$ had no or incomplete education, and the remaining $12.6 \%$ had a middle-school education or higher. Regarding residence, $75.8 \%$ of the patients lived in their own home, and $24.1 \%$ lived in a family member's home. The average evolution of AD from the approximate onset of symptoms until participation in the study was 3.8 years $(\mathrm{SD}=1.6$; range $=$ one to eight years). The average score on the CAMCOG-R was 51.5 points $(\mathrm{SD}=13.3$; range $=22$ to 86 ), 
the average $\mathrm{DAD}$ score was 23.5 points $(\mathrm{SD}=9.4$; range $=0$ to 40$)$, and the average overall NPI score was 16.3 points $(\mathrm{SD}=18.2$; range $=0$ to 106$)$.

The average caregiver age was 59.7 years $(\mathrm{SD}=13.6$; range $=26$ to 86 years). Women accounted for $66.6 \%$ of the caregivers. More than half $(58.8 \%)$ of the caregivers were the children of the patients, and there was a higher percentage of daughters than sons $(72.0 \% \mathrm{vs}$. $28.0 \%)$. Most of the caregivers (61.2\%) lived with the patient, $28.4 \%$ administered care five days a week or more, and the remaining $1.3 \%$ provided care less than five days a week. The average $\mathrm{BI}$ score was 43.6 points $(\mathrm{SD}=14.3$; range=22 to 87$)$, the "physical and social burden" factor was 14.2 points $(\mathrm{SD}=6.8$; range $=0-28)$, the "stress" factor was 6.4 points $(\mathrm{SD}=3.6$; range $=0-15)$, the "feelings of guilt" factor was 3.0 points $(\mathrm{SD}=1.9$; range $=0-8)$, the "emotional stress" factor was 4.9 points $(\mathrm{SD}=2.6$; range=0-10), and the "relationship of dependence" factor was 12.0 ( $\mathrm{SD}=4.1$; range=0-17). For the ERS, 23 cases demonstrated the spontaneous expression of deficits and concern regarding these deficits $(18.5 \%$; CI-95\% $=$ 11.3 to 25.8$)$; 34 cases mentioned having difficulties after performing specific tests $(28.4 \%$; CI $95 \%=19.2$ to 35.7 ); 37 cases made reference to deficits following direct questions, although they minimized the frequency and consequences of these deficits $(29.8 \%$; CI$95 \%=21.4$ to 38,3$)$; and 30 patients denied the presence of deficits $(24.0 \%$; CI-95\% $=16.3$ to 32.2). The cases in the final category (denial of deficits) were considered to have anosognosia. Table 1 describes the patient and caregiver characteristics that were stratified according to the presence or absence of anosognosia.

For the adjusted linear regression model $\left(\mathrm{r}^{2}=.426\right)$, increases in the total BI score were associated with greater degrees of anosognosia on the ERS (standardised beta $[\beta s]=.346$; $\mathrm{p}<.001)$, lower scores on the CAMCOG-R $(\beta \mathrm{s}=-.272 ; \mathrm{p}=.001)$, lower scores on the DAD $(\beta s=-.236 ; p=.017)$ and higher scores on the NPI $(\beta s=.245 ; p=.005)$ and cohabitation with the patient $(\beta s=.226 ; p=.004)$. According to the contribution indices, the ERS explained $14.7 \%$ of 
the total variance, the CAMCOG-R explained $11.6 \%$, the DAD explained $11.1 \%$, and cohabitation with the patient explained $9.6 \%$. If we stratify the patients by mild or moderated dementia we observed that the anosognosia increase associated with much deterioration.

Table 2 presents the adjusted regression models for each of the BI factors, and it emphasises only the significant values of the independent variables introduced. The presence of anosognosia (assessed with the ERS) was associated with the factors Physical and Social burden, emotional stress and relationship of dependence. The contribution indices of the ERS for each factor are also shown. Other social characteristics of the patients, were not related to anosognosia in the regression models.

\section{DISCUSSION}

The primary objective of the study was to determine the effect of AD patients' anosognosia on their caregivers' perception of burden. The results show that the presence of anosognosia and the patients' and caregivers' clinical or demographic characteristics increase caregiver burden. This association is similar to the association that was found in the first studies that were conducted with this hypothesis (DeBettignies, 1990; Seltzer, 1997).

The clinical characteristics that are related to $\mathrm{AD}$ are the main factors that increase caregiver burden, which has been described in the majority of the existing models (Peralin, 1990; Hebert, et al. 2006; Noyes, 2010). Cognitive deterioration, functional disability and the presence of PBSD are the core primary factors. In the majority of studies, anosognosia has been associated with greater deterioration in the evolutionary course of the illness; however, it can also present in the initial stages of $\mathrm{AD}$ and has been described in cases of mild cognitive decline (Clare, 2003; Starkstein 2006; Vasterling, 1997). Therefore, we can establish that the presence of anosognosia is an independent factor that directly influences the increase in perceived caregiver burden. 
The presence of anosognosia accounts for $14.7 \%$ of the total variance of caregiver burden. This percentage is similar to the percentage that was expressed in the Seltzer et al. study (1997). The effect is elevated and slightly greater than the percentage of variance that was explained by the most relevant factors, including cognitive decline, functional disability and cohabitation with the patient.

Caregiver burden is multidimensional and is related to the patient's clinical and sociodemographic aspects, caregiver characteristics and the nature of the previous relationship between the patient and caregiver (Turró-Garriga, 2007; Bédard, 1999). The BI is the burden assessment tool that is most commonly used in dementia studies, and its variables include physical and emotional aspects. Therefore, in this study, we used a factorial distribution that allowed us to determine that the presence of anosognosia has greater repercussions on physical and social burden, emotional stress and the relationship of dependence; however, it does not affect stress or feelings of guilt (Turró-Garriga, 2008).

Anosognosia's contribution to physical and social burden (15.5\%) suggests that it is responsible for greater social and physical limitations. Furthermore, the physical and social burdens are altered when the caregiver lives with the patient. Anosognosia is associated with risky behaviour, disinhibition and/or denial of the need for help. All of these factors suggest an increased demand on the caregiver's time, and supervision and the avoidance of risky behaviours are particularly affected (Clare, 2004).

For the relationship of dependence factor, we observed that anosognosia increases the caregiver's level of commitment and responsibility regarding caregiving tasks, which increases his or her feelings of isolation and loneliness (Zannetti, 1999; Dourado, 2007). This factor was more intense among those caring for older patients. Sex differences were significant only for this dimension, and according to some authors, these differences can be attributed to the idea that women express their thoughts and emotions more, perform more 
intimate tasks (e.g, hygiene) and/or that men receive more help from others than do women in the same circumstances (Bédard, 1999; Berger, 2005; Rinaldi, 2005).

Emotional stress was primarily related to the presence of PBSD, although the frequency and overall severity of the PBSD was low. Other authors have highlighted its relationship with the presence of disinhibition, irritability, apathy or psychotic disorders (Starkstein 2007; Starkstein 2010; Kashiwa, 2005). In a previous study, emotional stress was related to higher levels of patient apathy and anxiety (Turró-Garriga, 2008). The presence of these factors provokes a substantial increase in caregiver burden because the patient's difficulty in performing daily activities requires the caregiver to dedicate more time to the patient. This situation becomes more difficult, for example, when the patient displays caregiver persecution syndrome.

In our study, the feelings of guilt factor did not demonstrate a significant relationship with anosognosia. This lack of association (as with the stress factor) may have occurred because this factor is independent of patient characteristics. Previous studies (Conde-Sala, et al, 2010; Turró-Garriga, 2008) have found that guilty feelings were related to fewer opportunities for the caregiver to provide assistance, and they primarily affected daughters who did not live with the patient or who could not dedicate enough time to caregiving due to other work or family responsibilities.

This study presents some limitations that should be considered when interpreting the results. The anosognosia assessment still has multiple conceptual restrictions; consequently, the available evaluation tools also have their limitations. When the results are compared with those of other studies, the methods by which anosognosia was evaluated should be considered. The first limitation of this study relates to the dichotomous interpretation of anosognosia that was assumed. The interpretation was based on the cases that were classified in the last categories of the ERS, which may constitute a bias in the patient classification. 
Similarly, the overall assessment of anosognosia may not reflect the cases with a more specific or focused anosognosia (whether cognitive, behavioural or functional). A second limitation relates to the use of a clinical judgement scale in a cross-sectional study. Clinical assessments can also imply bias because they may have a limited evaluation framework in the clinical office environment, conditions that assume a patient-therapist relationship and an inability to compare the information with more objective methods. However, measures such as patient-caregiver discrepancies can also be directly altered by caregiver burden itself (Clare, 2004; Leicht, 2010). Third, we must consider that the evaluation of burden in this study was evaluated with the caregivers of $\mathrm{AD}$ patients but without stratification according to the severity of the disease. An increase in the sample size and the scale of disease severity using valid classification instruments would permit comparisons that could determine whether differences exist between the groups of caregivers because burden tends to increase with disease development, and anosognosia is more common among patients in more severe stages of AD (Garre-Olmo, 2000; Aalsten, 2006). Fourth, an other limitation of the study is due to the lack of information related to alcohol consumption of the participants. The chronic alcohol intake is related to damage of the central nervous system and specifically of the brain prefrontal regions that have been associated with anosognosia [Salmon E, Ruby P, Perani D, et al. 2006]. Finally, we have not specified the clinical stage of the patients (mild or moderate) because we included the CAMCOG-R, DAD and NPI punctuations directly in the linear regression models as well as, the adjusted regressions models allow identifying the specific relevance of each independent variable.

\section{CONCLUSIONS}

From the study results, we can conclude that anosognosia has important implications for the caregiver's perception of physical and emotional burden. The most relevant consequences of 
anosognosia are greater difficulty controlling the patient, less adherences to pharmacological and non-pharmacological treatments and early institutionalisation. These factors generate more burden for the caregiver, induce social isolation, increase the time dedicated to the patient and create more personal tension in caregiving tasks (Madalia \& Thysen, 2008; Koltai, 2001; Awad \& Voruganti, 2008; Clare, 2003).

Anosognosia increases perceived burden and implies greater wear on caregivers. At the same time, it is associated with an increase in the use of health care and social and health resources; institutionalisation is the maximum expression of this increased use (Berger, 2005; Badia-Llach, 2004). Currently, no existing resources are specific to the treatment of anosognosia or the caregivers of anosognosia patients. Therefore, it would be beneficial for the caregiver if specialised assistance programs or primary care providers offered general information upon diagnosis, information regarding the specific and individual characteristics of these patients and information regarding the availability of existing social and health resources.

The result of this study suggest that it will be much comfortable for caregivers if the physicians give more structured information, show guidelines for organize the daily assistance and explain how to facilitate the interaction with the patient. In patients with anosognosia, it is necessary to refuse the confrontation with patient and to increase the surveillance measures, as well as to try to maintain good physical and social activity and some responsibilities in like maintain the garden, walking out the dog, make the breakfast, etc. 


\section{REFERENCES}

- Aalsten P, van Valen E, de Vugt M-E, Lousberg R, Jolles J, Verhey F-R. 2006. Awareness and behavioral problems in dementia patients: a prospective study. Int Psychogeriatr 18: 3-17.

- Awad A-G, Voruganti L-N. 2008. The burden of schizophrenia on caregivers: a review. Pharmacoeconomics 26: 149-162.

- Badia-Llach X, Lara-Suriñach N, Roset-Gamisans M. 2004. Calidad de vida, tiempo de dedicación y carga percibida por el cuidador principal informal del enfermo de Alzheimer. Aten Primaria 34: 170-177.

- Bédard M, Cambers L, Molloy D-W, Lever J-A, Stones M-J, Martin N-J. 1999 The impact of Alzheimer's disease on caregivers is a gender-specific. Ann R Coll Physicians Surg Can 32: 21-28.

- Berger G, Bernhardt T, Weimer E, Peters J, Kratzsch T, Frolich L. 2005. Longitudinal study on the relationship between symptomatology of dementia and levels of subjective burden and depression among family caregivers in memory clinic patients. J Geriatr Psychiatry Neurol 18: 119-128.

- Bisiach E, Vallar G, Perani D, Papagno C, Berti A. 1986. Unawareness of disease following lesions of the right hemisphere: Anosognosia for hemiplegia and anosognosia for hemianopia. Neuropsychologia 24: 471-482.

- Burns A, Rabins P. 2000 Carer burden dementia. Int J Geriatr Psychiatr, 15, S9-13.

- Clare L. 2003. Managing threats to self: awareness in early stage Alzheimer's disease. Soc Sci Med 57: 1017-1029.

- Clare L. 2004.The construction of awareness in early-stage Alzheimer's disease: a review of concepts and models. British Journal of Clinical Psychology 43: 155-175. 
- Clyburn L-D, Stones M-J, Hadjistavropoulos T, Tuokko H. 2000. Predicting caregiver burden and depression in Alzheimer's disease. J Gerontol B Psychol Sci Soc Sci 55B: S2-13.

- Cohen J. 1992. A power primer. Psychol Bull, 112, 155-159.

- Conde-Sala J-L, Garre-Olmo J, Turró-Garriga O, Vilalta-Franch J, López-Pousa S. 2010. Differential features of burden between spouse and adult-child caregivers of patients with Alzheimer's disease: An exploratory comparative design. Int J Nurs Stud 48: 1262-1273.

- Cummings J-L, Mega M, Gray K, Rosemberg-Thompson S, Carusi D-A, Gornbein J. 1994. The Neuropsychiatric inventory. Comprehensive assesment of psychopathology in dementia. Neurology 44: 2308-2314.

- Debettignies B-H, Mahurin R-K, Pirozzolo F-J. 1990: Insight for impairment in independent living skills in Alzheimer's disease and multi-infarct dementia. J Clin Exp Neuropsychol 12: 355-63.

- Dourado M, Marinho V, Soares C, Engelhardt E, Laks J. 2007. Awareness of disease in Alzheimer's dementia: description of a mild to moderate sample of patient and caregiver dyads in Brazil. Int Psychogeriatr 19: 733-744.

- Finkel S, Burns A. 2000 Behavioral and psychological symptoms of dementia BPSD: A clinical and research update. Int Psychogeriatr 12: 9-12.

- Gaugler JE, Edwards AB, Femia EE, Zarit SH, Stephens MAP, Townsend A, Greene R. Predictors of institutionalization of cognitively impaired elders: Family help and the timing of placement. Journal of Gerontology: Psychological Sciences. 2000;55B:P247-P255. 
- Garre-Olmo J, Hernández-Ferrándiz M, Lozano-Gallego M, Vilalta-Franch J, TurónEstrada A, Cruz-Reina M-M, et al. 2000 Carga y calidad de vida en cuidadores de pacientes con demencia tipo Alzheimer. Rev Neurol 31: 522-527.

- Gelinas I, Gauthier L, McIntyre M, Gauthier S. 1999. Development of a functional measure for persons with Alzheimer's disease: the disability assessment for dementia. Am J Occup Ther 53: 471-481.

- Hebert R, Prigerson H, Schulz R, Arnold, R. 2006. Preparing caregivers for the death of a loved one: A theoretical framework and suggestions for future research. J Palliat Med 9: 1164-1171.

- Kashiwa Y, Kitabayashi Y, Narumoto J, Nakamura K, Ueda H, Fukui K. 2005. Anosognosia in Alzheimer's disease: association with patient characteristics, psychiatric symptoms and cognitive deficits. Psychiatry Clin Neurosci 59: 697-704.

- Koltai D-C, Welsh-Bohmer K-A, Schmechel D-E. 2001. Influence of anosognosia on treatment outcome among dementia patients [Special issue: Cognitive rehabilitation in dementia]. Neuropsychol Rehabil 11: 455-475.

- Leicht H, Berwig M, Gertz, H-J. 2010 Anosognosia in Alzheimer's disease: The role of impairment levels in assessment of insight across domains. J Int Neuropsychol Soc 16: $463-447$.

- Madalia A, Thysen J. 2008. Insight into neurocognitive dysfunction in schizophrenia. Schizophr Bull 34: 1221-123.

- Mahoney R, Regan C, Katoma C, Livingston G. 2005 Anxiety and depression in family caregivers of people with Alzheimer disease. The LASER-AD study. Am J Geriatr Psychiatr 13: 795-801. 
- Martín M, Salvadó I, Nadal S, Miji L-C, Rico J-M, Lanz P, et al. 1996. Adaptación para nuestro medio de la Escala de Sobrecarga del Cuidador Caregiver Burden Interview de Zarit. Revista de Gerontoloía 6: 338-46.

- Martín-Carrasco M, Franco-Martín M, Pelegrín C, Roy P, Iglesias C, Ros S, et al. 2009. Effectiveness of a psychoeducational intervention program in the reduction of caregiver burden in alzheimer's disease patients' caregivers. Int J Geriatr Psychiatr 24: 489-499.

- McKhann G, Drachman D, Folstein M, Katzman R, Price D, Stadlan EM. 1984. Clinical diagnosis of Alzheimer's disease: report of the NINCDS-ADRDA Work Group under the auspices of Department of Health and Human Services Task Force on Alzheimer's disease. Neurology 34: 939-44.

- Migliorelli R, Tesón A, Sabe L, Petracca G, Petracchi M, Leiguarda R, et al. 1995. Anosognosia in Alzheimer's disease: A study of associated factors. J Neuropsychiatry Clin Neurosci 8: 338-344.

- Noyes B-B, Hill R-D, Hicken B-L, Luptak M, Rupper R, Dailey N-K, et al. 2010. The role of grief in dementia caregiving. Am J Alzheimers Dis Other Demen 25: 9-17.

- Pearlin L, Mullan J, Semple S, Skaff M. 1990. Caregiving and the stress process: an overview of concepts and their measures. Gerontologist 3: 583-594.

- Rinaldi P, Spazzafumo L, Mastriforti R, Mattioli P, Marvardi M, Polidori M-C, et al. 2005. Predictors of high level of burden and distress in caregivers of demented patients: results of an Italian multicenter study. Int J Geriatr Psychiatr 2: 168-174.

- Roth M, Tym E, Mountjoy C-Q, Huppert F-A, Hendrie H, Verma S, et al. 1986. CAMDEX, a standardized instrument for the diagnosis of mental disorder in the elderly with special reference to the early detection of dementia. Br J Psychiatr 149: 698-709. 
- Salmon E, Perani D, Herholz K, Marique P, Kalbe E, Holthoff V, Delbeuck X, Beuthien-Baumann B, Pelati O, Lespagnard S, Collette F, Garraux G. 2006. Neural Correaltes of anosognosia for cognitive impairment in Alzheimer's disease. Hum Brain Mapp 27:588-97

- Seltzer B. Vasterling J-J, Yoder J, Thompson K-A. 1997. Awareness of deficit in Alzheimer's disease: relation to caregiver burden. Gerontologist 38: 20-24.

- Sörensen S, Pinquart M, Duberstein P. 2002 How effective are interventions with caregivers? An updated meta-analysis. Gerontologist 42: 356-372.

- Starkstein S-E, Jorge R, Mizrahi R, Robinson R-G. 2006 A diagnostic formulation for anosognosia in Alzheimer's disease. J Neurol Neurosurg Psychiatry 78: 719-725.

- Starkstein S-E, Jorge R, Mizrahi R, Adrian J, Robinson R-G. 2007 Insight and danger in Alzheimer's disease. Eur J Neurol 14: 455-46.

- Starkstein S-E, Brockman S, Bruce D, Petracca G. 2010 Anosognosia is a significant predictor of apathy in Alzheimer's disease. J Neuropsychiatry Clin Neurosci 22: 378383.

- Turró-Garriga O. 2007. Repercusiones de la enfermedad de Alzheimer en el cuidador. Alzheimer Real Inv Dem 35: 30-37.

- Turró-Garriga O, Soler-Cors O, Garre-Olmo J, López-Pousa S, Vilalta-Franch J, Montserrat-Vila S. 2008. Distribución factorial de la carga en cuidadores de pacientes con enfermedad de Alzheimer. Rev Neurol 46: 582-588.

- Vasterling J-J, Seltzer B, Watrous W.E. 1997. Longitudinal assessment of deficit unawereness in Alzheimer's disease. Neuropsychiatry Neuropsychol Behav Neurol 1: 197-202. 
- Vilalta J, Llinàs J, López-Pousa S, Amiel J, Vidal C. 1990. The Cambridge Mental Disorders of the Elderly Examination. Validation of the Spanish adaptation. Neurologia 5: 117-120.

- Vilalta-Franch J, Lozano-Gallego M, Hernandez-Ferrandiz M, Llinàs-Regla J, LópezPousa S, López O-L. 1999. The Neuropsychiatric Inventory. Propiedades psicométricas de su adaptación al español. Rev Neurol 29: 15-19.

- Yueh-Feng L-Y, Guerriero-Austrom G. 2005. Distress responses and self-care behaviors in dementia family caregivers with high and low depressed mood. J Am Psychiatr Nurses Assoc 11: 231-24.

- Zannetti O, Geroldi C, Frisoni G-B, Bianchetti A, Trabucchi, M. 1999. Contrasting results between caregiver's report and direct assessment of activities of daily living in patients affected by mild and very mild dementia: the contribution of the caregiver's personal characteristics. J Am Geriatr Soc 47: 196-203.

- Zarit S-H, Reever K-E, Bach-Peterson, J. 1980. Relatives of the impaired elderly. Correlates of feelings of burden. Gerontologist 20: 649-54. 
Table 1. Description and analysis of the characteristics of patients and caregivers stratified according to presence or absence of anosognosia.

\begin{tabular}{|c|c|c|c|c|}
\hline & $\begin{array}{c}\text { Anosognosia } \\
n=30\end{array}$ & $\begin{array}{c}\text { No anosognosia } \\
\mathrm{n}=94\end{array}$ & $p$ & $\begin{array}{c}\text { Cohen's } \\
\quad d\end{array}$ \\
\hline \multicolumn{5}{|l|}{ PATIENTS } \\
\hline Age, mean (SD) & $78.7(8,0)$ & $79.1(6.6)$ & $.735^{\mathrm{a}}$ & \\
\hline Sex -women-, n (\%) & $23(76.3)$ & $61(64.9)$ & $.230^{\mathrm{b}}$ & \\
\hline CAMCOG-R, mean (SD) & $45.3(12.7)$ & $53.7(13.8)$ & $.002^{\mathrm{a}}$ & .63 \\
\hline $\mathrm{DAD}$, mean (SD) & $16.4(8,2)$ & $25.7(8,8)$ & $<.001^{\mathrm{a}}$ & 1.09 \\
\hline NPI, mean (SD) & $26.5(22.8)$ & $13.1(15.1)$ & $<.0 .001^{\mathrm{a}}$ & -.69 \\
\hline Time of evolution, mean (SD)* & $3.8(1.1)$ & $3.4(1.4)$ & .132 & \\
\hline Severity of dementia -mild-, n (\%) & $7(23.3)$ & $48(51.1)$ & .008 & \\
\hline \multicolumn{5}{|l|}{ CAREGIVERS } \\
\hline Age, mean (SD) & $62.1(1.7)$ & $59.8(14.2)$ & $.886^{\mathrm{a}}$ & \\
\hline Sex -women-, n (\%) & $19(63.3)$ & $64(68,1)$ & $.630^{\mathrm{b}}$ & \\
\hline Family relation -son/daughter-, n (\%) & $22(73.3)$ & $51(54.3)$ & $.096^{\mathrm{b}}$ & \\
\hline Frequency of contact, $n(\%)$ & & & $.709^{\mathrm{b}}$ & \\
\hline 1-4 days/week & $2(6.9)$ & $11(11.8)$ & & \\
\hline$\geq 5$ days/week & $8(26.7)$ & $27(28,7)$ & & \\
\hline Live with patient & $20(66.7)$ & $54(58.4)$ & & \\
\hline Burden Interview, mean (SD) & $31.6(15.7)$ & $18,6(12.5)$ & $<.001^{\mathrm{a}}$ & -.92 \\
\hline Factor 1 & $11.9(8.6)$ & $4.5(5.4)$ & $<.0011^{\mathrm{a}}$ & -1.03 \\
\hline Factor 2 & $3.5(4.4)$ & $2.1(3.2)$ & $.194^{\mathrm{a}}$ & \\
\hline Factor 3 & $1.2(2.3)$ & $.9(1.7)$ & $.594^{\mathrm{a}}$ & \\
\hline Factor 4 & $3.0(3.1)$ & $1.7(2.3)$ & $.011^{a}$ & -.47 \\
\hline Factor 5 & $13.3(4.3)$ & $10.7(4.0)$ & $.048^{\mathrm{a}}$ & -.62 \\
\hline
\end{tabular}

${ }^{a}$ U de Mann Whitney; ${ }^{b}$ Chi-square.

*time between first symptoms and participation in the study

$\mathrm{SD}=$ Standard deviation; $\mathrm{F} 1=$ physical and social burden, $\mathrm{F} 2=$ stress, $\mathrm{F} 3=$ feelings of guilt, $\mathrm{F} 4=$ emotional stress,

F5=relationship of dependence 
Table 2. Linear regression models by BI factors.

\section{Burden Interview dimensions}

\begin{tabular}{ccccc}
\hline physical and & Feelings of & Emotional & relationship of \\
social burden & Stress & guilt & Stress & dependence
\end{tabular}

\begin{tabular}{|c|c|c|c|c|c|c|c|c|c|c|}
\hline Variables $^{1}$ & Beta & $p$ & Beta & $p$ & Beta & $p$ & Beta & $p$ & Beta & $p$ \\
\hline ERS & .378 & $<.001$ & ns & -- & ns & -- & .227 & .014 & .203 & .010 \\
\hline Age $p$. & ns & -- & ns & -- & ns & -- & ns & -- & .177 & .025 \\
\hline Sex c. & ns & -- & ns & -- & ns & -- & ns & -- & .158 & .045 \\
\hline Marital Status p. & .174 & .022 & ns & -- & ns & -- & ns & -- & ns & -- \\
\hline Cohabitation & .227 & .004 & $\mathrm{~ns}$ & -- & -.253 & .006 & ns & -- & .472 & $<.001$ \\
\hline CAMCOG-R & -.260 & .001 & ns & -- & ns & -- & -.243 & .007 & ns & -- \\
\hline DAD & -.358 & $<.001$ & $\mathrm{~ns}$ & -- & ns & -- & ns & -- & ns & -- \\
\hline NPI & ns & -- & .431 & $<.001$ & ns & -- & .336 & $<.001$ & ns & -- \\
\hline $\mathrm{r}^{2}$ & \multicolumn{2}{|c|}{.452} & \multicolumn{2}{|c|}{.179} & \multicolumn{2}{|c|}{.054} & \multicolumn{2}{|c|}{.212} & \multicolumn{2}{|c|}{.301} \\
\hline $\begin{array}{c}\text { ERS contribution } \\
\text { Index }\end{array}$ & \multicolumn{2}{|c|}{$15.5 \%$} & \multicolumn{2}{|c|}{--} & \multicolumn{2}{|c|}{--} & \multicolumn{2}{|c|}{$4.8 \%$} & \multicolumn{2}{|c|}{$6.1 \%$} \\
\hline
\end{tabular}

p. $=$ patient; c. $=$ caregiver; ns $=$ no signification

${ }^{1}$ Variables in the first step of the linear regression models: ERS, sex of the patient, age's patient, patient marital status, patient's residence, CAMCOG-R, DAD, NPI, sex of the caregiver, age's caregiver, caregiver's relationship with the patient and cohabitation. 